\title{
UV-Visible Spectrophotometric as a Prospective Tool in Neonatal Sepsis
}

\author{
Eko Suhartono $^{1, *}$, Ari Yunanto ${ }^{2}$, Edi Hartoyo ${ }^{2}$, Nia Kania ${ }^{3}$, Adelia Anggraini Utama², \\ Ratih Kumala Sari ${ }^{2}$, Niarsari Anugrahing Putri ${ }^{2}$, Iskandar Thalib ${ }^{2,4}$ \\ ${ }^{1}$ Department of Medical Chemistry/Biochemistry, Faculty of Medicine, Lambung Mangkurat University, Jl. Ahmad Yani Km. 36, \\ Banjarbaru 70712, South Kalimantan, Indonesia \\ ${ }^{2}$ Department of Child Health, Faculty of Medicine, Lambung Mangkurat University, Jl. Veteran No. 128, Banjarmasin 70232, \\ South Kalimantan, Indonesia \\ ${ }^{3}$ Research Center for Toxicology, Cancer, and Degenerative Diseases, Department of Pathology, Ulin General Hospital/Faculty of Medicine, \\ Lambung Mangkurat University, Jl. Veteran No. 128, Banjarmasin 70232, South Kalimantan, Indonesia \\ ${ }^{4}$ Research and Development Unit, Mutiara Bunda Mother and Child Hospital, Jl. Taisir No. 2, Martapura 70614, South Kalimantan, Indonesia \\ *Corresponding author. E-mail: esuhartono@unlam.ac.id
}

Received date: Aug 17, 2017; Revised date: Nov 26, 2017; Accepted date: Jan 5, 2018

\section{Abstract}

$\mathrm{B}$ ACKGROUND: This study was aimed to employ the UV-Visible (UV-Vis) spectrophotometry techniques to detect the changes in the blood of neonatal sepsis (NS) subject for a deeper understanding in the pathomechanism of NS.

METHODS: The cross-sectional study was conducted from February to May 2017 in the Neonatology Division, Department of Pediatric, Ulin General Hospital/Faculty of Medicine, Lambung Mangkurat University, Banjarmasin, South Kalimantan, Indonesia. Blood specimens were taken from newborns, of which 15 each of newborns at risk of sepsis and without risk of sepsis. Data were analyzed by using Mann-Whitney U test.

\section{Introduction}

Neonatal sepsis (NS) is a clinical syndrome that is characterized by systemic signs and symptoms of infection in neonates which is an important cause of mortality in newborns and life-threatening disorder in infants.(1-2) Incidence rate of neonatal sepsis in developed countries ranged between 3-5 per 1,000 live births. In 2007, WHO reported the case fatality rate (CFR) in the case of neonatal sepsis in the world is still high by $40 \%$.(3) In 2015,
RESULTS: The result of this study suggested that there is a significant difference in the average of absorbance ratio parameter using UV-Vis spectrophotometric methods on the case group compared to the control group. Also, there is a significant difference between advanced oxidation protein products (AOPPs) and thiocyanate (SCN) level in newborn at risk of sepsis.

CONCLUSION: The present study demonstrated there were significant differences between the average of absorbance ratio parameter for protein and oxy-hemoglobin region using UV-Vis spectrophotometric methods in healthy subjects and newborn at risk of sepsis.

KEYWORDS: spectrophotometric, neonatal sepsis, oxidative stress

Indones Biomed J. 2018; 10(1): 74-8
4.5 million children died in the first year of life.(4) Fortyfive percents occurred in the first month of life (newborn babies). The causes of death in infants were various. NS contributed to seven percent of the total cause of infant mortality. $(5,6)$ The current gold standard for diagnosis of sepsis is blood culture, suffers from low sensitivity and a reporting delay of approximately 48-72 hours.(7)

The pathomechanism of NS remains unclear. Some previous studies suggested that the pathomechanism of NS was through oxidative stress mechanism.(2,8-9) Infectious agents in NS caused the activation neutrophils which 
promote a further reaction to activate nicotinamide adenine dinucleotide phosphate (NADPH) oxidase. This activation will cause the formation reactive oxygen species (ROS). Also, the activation of neutrophil-induced the releasing of myeloperoxidase (MPO). MPO use $\mathrm{H}_{2} \mathrm{O}_{2}$ to catalyzes the oxidation of halide $\left(\mathrm{Cl}^{-}, \mathrm{Br}\right)$ and pseudohalide (thiocyanate ion, $\mathrm{SCN}$ ) to form hypothiocyanous acid (HOSCN). The ROS, oxidized halide and pseudohalide is known to play an essential role in killing invading parasites and pathogens. Furthermore, the ROS, halide and pseudohalide oxidation products could oxidize protein and result in the formation of oxidized protein known as advanced oxidation protein products (AOPPs). $(2,10)$

UV-Visible (UV-Vis) spectrophotometric method was one known method that has been used extensively for several qualitative analysis of medical biological samples such as, blood plasma, sera, or tissues.(11) Spectrophotometry is a technique that measures the interaction of molecules with electromagnetic radiation. Furthermore, when the light was absorbed, a spectrum is obtained as a function of its frequency of wavelength. It depends on chemical nature on the molecular environment of its chromophores. This method is therefore an excellent technique for following ligandbinding reactions, enzyme catalysis and conformational transitions in proteins and nucleic acids.(12)

Generally, the blood experiences significant changes in compound and biochemical properties in all diseases. The use of an examination method such as UV-Vis spectrophotometric to determine changes in blood is an inevitability. This is due to reduction in time, resources and cost.(11) The advantage in the ever-improving sensitivity of contemporary spectrometers with sophisticated computational techniques proved that UV-Vis spectrophotometric could be exploited to explore the various biochemical alterations on the molecular and structural differences of the biofluids of the human body.(13)

In recent years, spectrophotometric was used for the diagnosis of several diseases. Kanagathara, et al., and Ibrahim, et al., have been employed UVVis spectrophotometric methods to study the spectral differences in the serum of normal blood samples. $(11,14)$ Gunasekaran, et al., has been demonstrated using UV-Vis spectrophotometric method to differentiate the healthy sera from jaundice, leukemia, anemia, cirrhosis liver, thalassemia and diabetes.(13,15-16) Still, there is no study in the literature examining the characteristics of blood in NS using UV-Vis spectrophotometric methods. Therefore, the present experimental study aimed to employ the UV-Vis spectrophotometric techniques to detect the changes in the blood of NS subject and also for a deeper understanding the pathomechanism of NS.

\section{Methods}

This cross-sectional study was conducted on infants with and without risk of sepsis after informed consent was obtained from them. It was approved by the Ethics Commission of the Faculty of Medicine, Lambung Mangkurat University, Banjarmasin, South Kalimantan, Indonesia. The protocol of this study was approved by the Ethics Committee of Faculty of Medicine, Lambung Mangkurat University (No. 331/KEPK-FK UNLAM/EC/IV/2017) according to the Declaration of Helsinki. The participants gave us their written informed consent before the study.

The study was conducted from February to May 2017 in the Neonatology Division, Department of Pediatric, Ulin General Hospital/Faculty of Medicine, Lambung Mangkurat University, Banjarmasin, South Kalimantan, Indonesia. All laboratory tests were conducted at Department of Medical Chemistry/Biochemistry, Faculty of Medicine Lambung Mangkurat University, Banjarbaru, South Kalimantan, Indonesia.

A total of 30 infants subjects were recruited for this study. Subjects were divided into 2 groups: group I were infants at risk of sepsis and served as a case group, while group II were infants without risk of sepsis and served as a control group. Subjects in the sepsis risk group were included on the basis of having at least 1 major criteria or 2 minor criteria for sepsis according to The American Congress of Obstetricians and Gynecologist (ACOG) guidelines.(17-18) Major risk criteria were premature ruptured of membranes (PROM) for $>24$ hours, maternal fever with intrapartum temperature $>38^{\circ} \mathrm{C}$, chorioamnionitis, fetal heart rate persisting at $>160$ times/minute or bad smelling of amniotic fluid. Minor risk criteria were PROM for $>12$ hours, maternal fever with intrapartum temperature $>37.5^{\circ} \mathrm{C}$, low Apgar score ( $<5$ at the 1 st $\min ,<7$ at the 5 th $\min$ ), very low birth weight baby (VLBWB) of $<1500$ gr, gestational age $<37$ weeks, multiple pregnancy, bad smelling of vaginal discharge, maternal urinary tract infection (UTI) or suspected untreated maternal UTI. Age and gender-matched healthy newborns were chosen as controls. Newborns with birth asphyxia, low birth weight, preterm and congenital malformations were excluded from this study. 


\section{Samples Collection}

Sampling was carried out by accidental sampling method, with criteria specified in subjects section as mentioned earlier. The sampling took place from February-May 2017. In that time, 30 samples were obtained, with 15 samples of newborn at risk of sepsis and 15 normal samples. Samples of blood were taken from umbilical cord (5 $\mathrm{mL}$ each) and collected using vacutainers containing ethylenediaminetetraacetic acid (EDTA). Each sample then washed with cold saline phosphate buffer with $\mathrm{pH} 7.4$ for the spectroscopic analysis, and the estimation of $\mathrm{SCN}$ and AOPPs levels.

\section{Spectrophotometry Analysis}

Each blood sample was diluted with normal saline at concentration of $5 \mu \mathrm{L} / \mathrm{mL}$. The spectra were scanned in the region between 200-700 $\mathrm{nm}$ using T $80^{+} \mathrm{UV}$-Vis spectrometer at Medical Chemistry/Biochemistry Laboratory, Faculty of Medicine, Lambung Mangkurat University, Banjarbaru, South Kalimantan, Indonesia. Amide chain of proteins present in the blood absorbs strongly at $210 \mathrm{~nm}$. Absorption of tyrosine and tryptophan is at around $280 \mathrm{~nm}$. Also the absorptions at 417, 543 and $578 \mathrm{~nm}$ are due to d-f transition of CO-Oxy-hemoglobin.(13,15) From these spectral differences, three absorbance ratio could be measured.(15) They were A278/A210 in the protein region and A543/ A417, A578/A417 in the oxy-hemoglobin region.

\section{SCN and AOPPs Level Analysis}

SCN concentration was measured spectrophotometrically as described by Aune and Thomas. AOPPs measurement were made by spectrophotometric methods as describe by Witko-Sarsat, et al., with slight modification.(10)

\section{Statistical Analysis}

The comparison of absorbance between healthy blood and risk of sepsis blood were examined by Mann Whitney U-test with $p<0.05$. Data analysis using SPSS for Windows version 16 (SPSS Inc., Chicago, Illinois, USA).

\section{Results}

In this present study, we tried to employ the spectral differences between healthy blood and blood of newborn at risk of sepsis. The result is presented in Table 1. It gives the statistical results of the analysis of UV-Visible spectral data in protein and oxy-hemoglobin.
Table 1. UV-Visible spectral analysis of absorbance ratio parameters of healthy and newborn at risk of sepsis.

\begin{tabular}{cccc}
\hline Region & $\begin{array}{c}\text { Intensity ratio } \\
\text { parameter }\end{array}$ & Average \pm SD & $\boldsymbol{p}$-value \\
\hline \multirow{3}{*}{ Protein } & $\mathrm{A}_{278} / \mathrm{A}_{210}$ & & \\
& Normal & $13.950 \pm 5.714$ & 0.000 \\
& Sepsis & $1.963 \pm 0.776^{*}$ & \\
\hline & $\mathrm{A}_{543} / \mathrm{A}_{417}$ & & \\
& Normal & $1.725 \pm 0.758$ & 0.000 \\
Oxy-hemoglobin & Sepsis & $0.852 \pm 0.252^{*}$ & \\
\cline { 2 - 4 } & $\mathrm{A}_{578} / \mathrm{A}_{417}$ & & \\
& Normal & $1.543 \pm 0.876$ & 0.000 \\
& Sepsis & $1.258 \pm 0.126^{*}$ & \\
\hline
\end{tabular}

*Values are significantly different from $(p<0.05)$ from the normal group, according to Mann-Whitney U-tests.

Meanwhile to investigate how the protein damage during sepsis condition, in this present study we also measured the level of SCN and AOPPs. The results are shown in Table 2. The result from Table 2 shows that the level of SCN is higher in the case group compared to control group.

Table 2. SCN and AOPPs level comparison between case and control group.

\begin{tabular}{lccc}
\hline \multicolumn{1}{c}{ Parameters } & Control group & Case group & $\boldsymbol{p}$-value \\
\hline SCN $(\mathrm{mM})$ & $0.232 \pm 0.053$ & $0.667 \pm 0.053^{*}$ & 0.001 \\
AOPPs $(\mu \mathrm{M})$ & $0.724 \pm 0.968$ & $3.867 \pm 1.340^{*}$ & 0.000 \\
\hline
\end{tabular}

SCN: thiocyanate; AOPPs: advanced oxidation protein products. $*$ Values are significantly different from $(p<0.05)$ from the normal group, according to Mann-Whitney U-tests.

\section{Discussion}

Spectrophotometry method technique has become a promising tool for a better understanding of pharmaceutical, biological material, and pathomechanism of a disease. It was first described by Gunasekaran, et al., who investigated the spectral differences of several diseases like diabetes, leukemia and thyroid.(13,15-16)

Table 1 gives the statistical results of the analysis of UV-Visible spectral data in protein and oxy-hemoglobin. The data shows the discrimination of the newborn at risk of sepsis blood from that of the healthy one. The result data indicated that the absorbance ratio of 
oxy-hemoglobin is lower in newborn at risk of sepsis. The decreasing of this ratio may be due to the changes in oxyhemoglobin.

It is well known that sepsis will activate the natural immune system which are mostly ruled by neutrophils. In this condition, neutrophil will have inserted into infected tissue to induce a process known as respiratory burst. This process uses an oxygen to form ROS which is useful to attack the bacterial pathogens.(2) The result clearly indicated that there is a structural changes in oxy-hemoglobin This is thought to be due to oxygen release from oxy-hemoglobin used to produce ROS such as radical superoxide $\left(\mathrm{O}_{2}\right)$, hydrogen peroxide $\left(\mathrm{H}_{2} \mathrm{O}_{2}\right)$ and radical hydroxyl. Also, the release of oxygen from oxy-hemoglobin will lead to hypoxia. Hypoxia itself will increased the ROS level. The basic mechanism how the hypoxia increased the ROS level is mitochondria dysfunction which is activate some of the enzymes that play a role in the formation of ROS-like NADPH oxidase and superoxide dismutase (SOD).(19)

The result data from Table 1 also shows that the absorbance ratio of protein is also lower in newborn at risk sepsis. This result indicated that the protein levels in blood of newborn at risk of sepsis was decreased. This may be due to protein damage due to oxidative stress conditions. To investigate how the protein damage during sepsis condition, in this present study we also measured the level of SCN and AOPPs (Table 2).

Table 2 shows that the level of SCN is higher in the case group compared to control group. It is in line with our previous reports which investigated the comparison of SCN levels in saliva of newborn at risk of sepsis with and without antibiotic therapy. The level of SCN seems higher at newborn with the risk of sepsis without antibiotic therapy.(10) The increasing of SCN level may be due to the activation of MPO which is used $\mathrm{H}_{2} \mathrm{O}_{2}$ and $\mathrm{SCN}$ as a co-substrate to form HOSCN which is also useful to attack bacterial pathogens.(20)

Both ROS and HOSCN that produced in sepsis condition are potential oxidants which promote a further reaction result in host tissue damage.(21) One of the targets that can be damaged by the molecule is protein. It is in line with the result from the Table 2. The result from Table 2 indicated that the level of AOPPs is increased. AOPPs are known as a novel marker in several conditions which is related to oxidative stress.(10) AOPPs is known as a cross-linking protein products which are formed by a modification of amino acid caused by oxidation by a ROS. $(22-23)$

\section{Conclusion}

In conclusion, the present study demonstrated there were significant differences between the average of absorbance ratio parameter for protein and oxy-hemoglobin region using UV-Vis spectrophotometric methods in healthy subjects and newborn at risk of sepsis. It can be concluded that there were changes in blood of newborn at risk of sepsis and it may explain the pathomechanism of neonatal sepsis for our better understanding. This result study also suggests that UV-visible spectrophotometric may be useful as a tool for early diagnosis of NS. Further research is needed to explore spectrophotometric analysis as a diagnosis method of NS.

\section{References}

1. Bokun LV, Huang J, Yuan H, Yan W, Hu G, Wang J. Tumor necrosis factor-alpha as a diagnostic marker for neonatal sepsis: A meta-analysis. Scientific World J. 2014; 2014: 1-14. doi: $10.1155 / 2014 / 471463$.

2. Yunanto A, Firdaus RT, Triawanti, Suhartono E. Advance oxidation protein products (AOPPs) of newborn at risk of sepsis as novel parameter for early-onset neonatal sepsis. Int J Biosci Biochem Bioinforma. 2014; 4: 90-3.

3. Simarmata YBC, Harahap U, Djipta GD. Identification of risk factors caused neonatal sepsis of premature neonatus in Adam Malik General Hospital Center. Int J PharmTech. 2016; 9: 54-7.

4. World Health Organization [Internet]. Global Health Observatory Data: Infant Mortality [update 2017; cited 2017 Jun 13]. Available from: http://www.who.int/gho/child_health/mortality/neonatal_ infant/en/.

5. World Health Organization [Internet]. Global Health Observatory Data: Causes of Child Mortality [cited 2017 Jun 13]. Available from: http://www.who.int/gho/child_health/mortality/causes/en/.

6. World Health Organization [Internet]. Global Health Observatory Data: Neonatal Mortality. [cited 2017 Jun 13]. Available from: http://www.who.int/gho/child_health/mortality/neonatal_text/en/.

7. Venkatesh M, Flores A, Luna RA. Molecular microbiological methods in the diagnosis of neonatal sepsis. Expert Rev Anti Infect Ther. 2010; 9: 1037-48.

8. Fink MP. Cytopathic hypoxia: Mitochondrial dysfunction as mechanism contributing to organ dysfunction in sepsis. Crit Care Clin. 2001; 1: 219-37.

9. Cancelier AC, Petronilho F, Reinke A, Constantino L, Machado R, Ritter C, Dal-Pizzol F. Inflammatory and oxidative parameters in cord blood as diagnostic of early-onset neonatal sepsis: A casecontrol study. Pediatr Crit Care Med. 2009; 10: 467-71.

10. Yunanto A, Iskandar, Suhartono E. In-vitro effects of some antibiotic drugs on saliva thiocyanate and oxidation protein products levels on newborn at risk of sepsis. IJPCR. 2016; 8: 86-9.

11. Ibrahim MSM, Bajaj MM, Singh VR, Ruchika, Farhana SAS Spectroscopic study of blood samples using FTIR and UV-Visible spectrometers. Internat J Bioscience. 2014; 3: 13-6. 
12. Schmid F. Biological Macromolecules: UV-visible Spectrophotometry. Encyclopedia of Life Sciences. 2001; 1-4. doi: 10.1038/npg. els.0003142.

13. Gunasekaran S, Natarajan RK, Renganayaki V, Rathikha R. FTIR and UV visible spectrophotometric approach to discriminate leukemic sera. Asian J. Spectro. 2008; 20: 2521-30.

14. Kanagathara N, Thirunavukkarasu M, Jeyanthi EC, Shenbagarajan P. FTIR and UV-Visible spectral study on normal blood samples. Int. J Pharm Bio Sci. 2011; 1: 74-81.

15. Gunasekaran S, Nataraian RK, Renganayaki V. UV Visible Spectrophotometric Approach and Absorption Model for the Discrimination of Diseased Blood. Asian J Chem. 2008; 20: 48-54.

16. Gunasekaran S, Uthra D. FTIR and UV-Visible spectral study on normal and jaundice blood samples. Asian J.Chem. 2008; 20: 5695703.

17. Bryce J, Boshi-Pinto C, Shibuya K, Black RE. WHO estimates the causes of death in children. Lancet. 2005; 365: 1147-52.

18. Aggarwal R, Sarkar N, Deorari AK, Paul VK. Sepsis in the newborn. Indian J Pediatr. 2008; 75: 261-6.
19. Gao J, Ding XS, Zhang YM, Dai DZ, Liu M, Zhang C, Dai Y. Hypoxia/oxidative stress alters the pharmacokinetics of CPU86017RS mitochondrial dysfunction and NADPH oxidase activation. Acta Pharm Sinica. 2013; 34: 1575-84.

20. Lestarisa T, Alexandra FD, Jelita H, Suhartono E. Myeloperoxidase as an indicator of liver cells inflammation induced by mercury. IJPCR. 2016; 8: 1516-21

21. Lane AE, Tan JTM, Hawkins CL, Heather AK, Davies MJ. The myeloperoxidase-derived oxidant $\mathrm{HOSCN}$ inhibits protein tyrosine phosphatases and modulates cell signalling via the mitogenactivated protein kinase (MAPK) pathway in macrophages. Biochem J. 2010; 430: 161-9. doi: 10.1042/BJ20100082.

22. Suhartono E, Nijka JA, Anhar VY, Sari RA, Edyson, Marisa D. Antilipid peroxidation activities of three selected fruits juices against cadmium induced liver damage in vitro. J. Trop Life Science. 2015; 5: 77-9.

23. Aflanie I, Sari NN, Suhartono E. Oxidative and chlorinative stress biomarkers in liver cells of rats exposed to cyanide in-vitro. IJPCR. 2016; 8: 1441-5. 